\title{
Seismotectonics in the Tanzawa Mountains area in the Izu-Honshu collision zone of central Japan, as revealed by precisely determined hypocenters and focal mechanisms
}

\author{
Yohei Yukutake ${ }^{1}$, Tetsuya Takeda ${ }^{2}$, Ryou Honda ${ }^{1}$, and Akio Yoshida ${ }^{1}$ \\ ${ }^{1}$ Hot Springs Research Institute of Kanagawa Prefecture, 586 Iriuda, Odawara, Kanagawa 250-0031, Japan \\ ${ }^{2}$ National Research Institute for Earth Science and Disaster Prevention, Tennodai 3-1, Tsukuba, Ibaraki 305-0006, Japan
}

(Received May 12, 2011; Revised August 31, 2011; Accepted September 22, 2011; Online published March 12, 2012)

\begin{abstract}
We investigate the detailed distribution of hypocenters and focal mechanisms beneath the Tanzawa Mountains, central Japan, where the Izu-Bonin arc has collided into the central part of the Honshu arc. Remarkable differences are found to exist between the hypocenter distributions in the western and eastern parts. The hypocenters of earthquakes in the eastern part tend to be distributed in a horizontal zone, whereas those in the western part are distributed in a volume. The focal mechanisms in the eastern part are right-lateral reverse faulting mechanisms, and one of the nodal planes is consistent with the geometry of the Philippine Sea (PHS) plate in the region. These results suggest that most earthquakes in the eastern part occur along the upper surface of the subducting PHS plate. In contrast, the focal mechanisms in the western part, especially deep in the western part, exhibit a different feature. The stress states in these two regions are found to be significantly different. The maximum and minimum principal stress axes in the eastern part are slightly inclined, whereas those in the western part are oriented in approximately the vertical and horizontal directions, respectively. The stress field in the eastern part may be caused by a slab pull force induced from the deeper part of the subducted plate.
\end{abstract}

Key words: Tanzawa Mountains, collision zone, hypocenter distribution, focal mechanism, stress field.

\section{Introduction}

The Tanzawa Mountains are located in the Izu-Honshu collision zone, where the Izu Bonin arc on the Philippine Sea (PHS) plate has been colliding into Honshu island on the Eurasian plate. The Tanzawa Mountains are thought to be fragments of the Izu-Bonin arc that have accreted onto the Honshu block. Several tectonic faults, such as the Tonoki-Aikawa Tectonic Line and the Kozu-Matsuda Fault have developed around the area (e.g., Taira et al., 1998; Arai et al., 2009). The configuration of the subducting PHS plate in and around this region has been estimated based on the hypocenter distribution, $S-P$ converted waves, seismic velocity tomography, and the seismic profile (e.g., Ishida, 1992; Iidaka et al., 1990; Tsumura et al., 1993; Matsubara et al., 2005; Sato et al., 2005). Kobayashi and Koketsu (2005) estimated that the rupture of the 1923 great Kanto earthquake extended to the region beneath the Tanzawa Mountains.

The seismicity beneath the Tanzawa Mountains is particularly high (e.g., Noguchi and Yoshida, 1991). Yoshida (1993) found that the characteristics of the hypocenter distribution are different between the western and eastern parts of the region. However, the relationship between the subducting process of the PHS plate and the seismicity in the region is not well understood. One of the crit-

Copyright (C) The Society of Geomagnetism and Earth, Planetary and Space Sciences (SGEPSS); The Seismological Society of Japan; The Volcanological Society of Japan; The Geodetic Society of Japan; The Japanese Society for Planetary Sciences; TERRAPUB. ical problems is whether the seismicity beneath the Tanzawa Mountains is caused by the subduction process of the PHS plate or by the collision between the Izu and Honshu blocks. In order to solve the seismotectonic problem, it is necessary to determine the hypocenters and focal mechanisms precisely. We relocated the hypocenters of the earthquakes that occurred under the Tanzawa Mountains based on the double-difference relocation method (DD method) (Waldhauser and Ellsworth, 2000) using the differential arrival times obtained by both manual picking and waveform cross-correlation analysis. We determined the focal mechanism from the absolute $P$ - and $S H$-wave amplitudes by adding the $P$-wave polarities. Furthermore, we analyzed the characteristics of the stress field using the stress inversion method.

\section{Data and Method}

We used data from 107 permanent online stations operated by the Hot Springs Research Institute of Kanagawa Prefecture (HSRI), National Research Institute for Earth Science and Disaster Prevention (NIED) Hi-net (Obara et al., 2005), and the Japan Meteorological Agency (JMA) (Fig. 1). We analyzed approximately 4,500 earthquakes that occurred in the rectangular region shown in Fig. 1, during the period from January 1, 2001 through June 1, 2008. The magnitudes of these earthquakes range from 0.5 to 5.0. The $P$ - and $S$-wave arrival times, the $P$-wave polarities, and the maximum amplitudes were picked manually. 


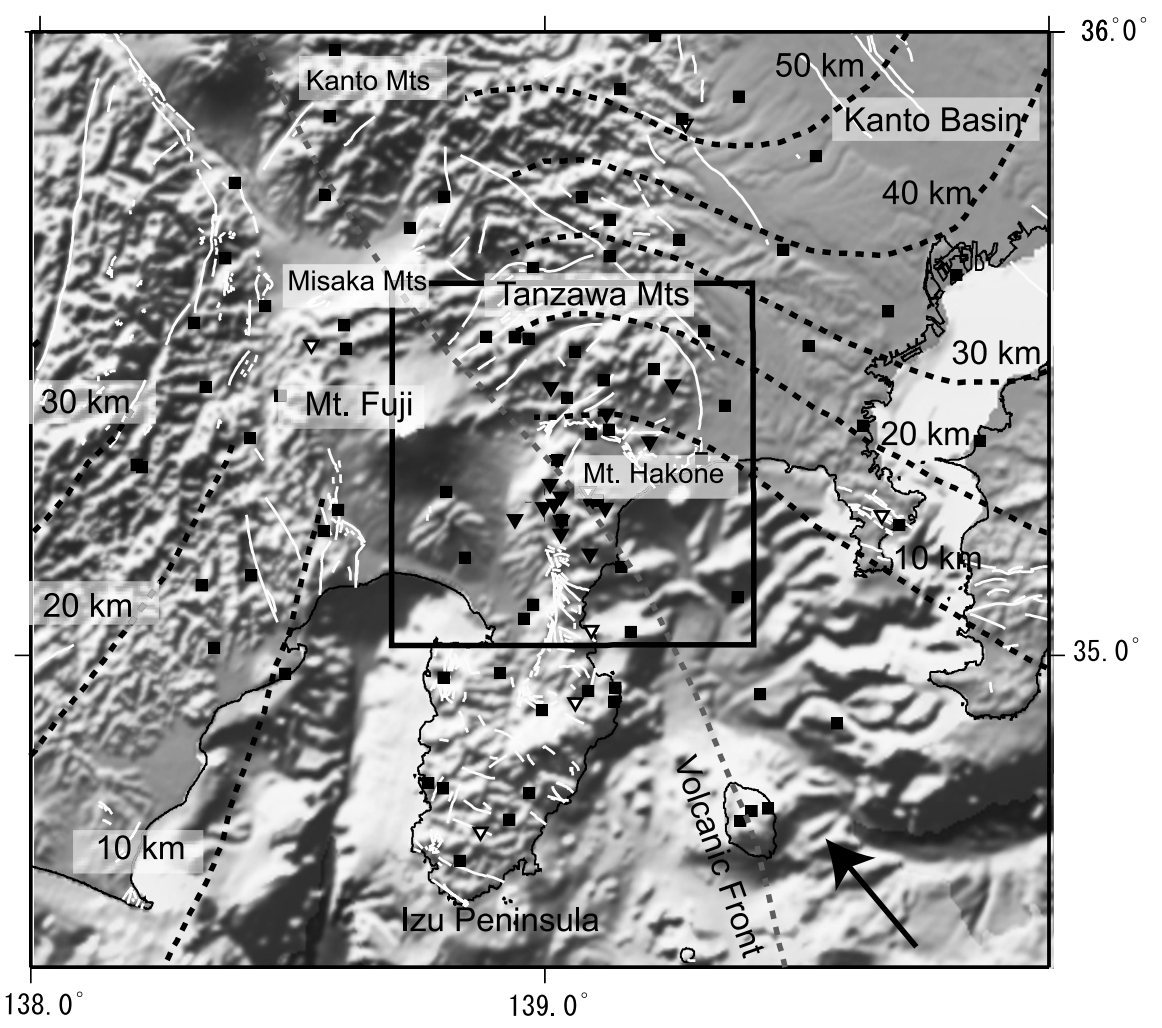

Fig. 1. Tectonic map in and around the Izu-Honshu collision zone. The black broken lines show the depth contours of the upper surface of the Philippine Sea (PHS) plate beneath Kanto region, as estimated by Ishida (1992). The gray broken line indicates the location of the volcanic front as reported by Kaizuka (1975). The PHS plate is subducting northwestward beneath the Eurasian plate at a rate of 4 to $5 \mathrm{~cm} / \mathrm{yr}$, as indicated by the black arrow (Seno, 1993). The squares and solid and open triangles indicate the locations of the stations used in the present study (squares: NIED Hi-net, solid triangles: HSRI, open triangles: JMA). The rectangle indicates the region shown in Fig. 2.

\subsection{Hypocenter relocation using the DD method}

In order to determine the initial hypocenters for the DD relocation, we used the one-dimensional velocity structure in the Tanzawa region estimated by Hiraga (1987). We applied the $P$ - and $S$-wave arrival times at stations within a distance of $80 \mathrm{~km}$ from each epicenter to the hypomh algorithm (Hirata and Matsu'ura, 1987). The DD method was applied to the double-difference data using these initial hypocenters. The differential arrival times for the manually picked $P$ - and $S$-waves were 548,454 and 494,403 pairs, respectively. We also used the differential arrival times obtained by the waveform cross-correlation analysis. The correlation measurements were conducted using the velocity waveform of a 0.75 -s time window and a $3-20 \mathrm{~Hz}$ bandpass filter, including the manually picked $P$ - or $S$-wave arrival times. We used only double-difference data with normalized cross-correlation coefficients 0.80. Adopting this threshold, we obtained cross-correlation data containing $186,933 P$-wave observations and $87,581 S$-wave observations. Using both the manually picked and cross-correlation data, $96 \%$ of the earthquakes were relocated. After the application of the DD method, the root mean square (RMS) of the double-difference time residual decreased from $192 \mathrm{~ms}$ to $130 \mathrm{~ms}$ for the manually picked data and from $87 \mathrm{~ms}$ to $6 \mathrm{~ms}$ for the cross-correlation data.

In order to assess the uncertainty in the hypocenter location, we applied the bootstrap resampling method (Shearer,
1997; Waldhauser and Ellsworth, 2000) to all of the relocated events. As a result, the average relative location errors were $0.017 \mathrm{~km}$ in the EW direction, $0.015 \mathrm{~km}$ in the NS direction, and $0.023 \mathrm{~km}$ in the depth direction for the earthquakes that were relocated using both the manually picked and cross-correlation data. These events correspond to $68 \%$ of all relocated earthquakes. For the events that were relocated using only the manually picked data, the average location errors were $0.123 \mathrm{~km}$ in the EW direction, $0.106 \mathrm{~km}$ in the NS direction, and $0.188 \mathrm{~km}$ in the depth direction.

\subsection{Focal mechanism determination}

In order to improve the reliability of the focal mechanism solution, we used the absolute amplitudes of the $P$ and $S H$-waves as well as the $P$-wave polarities. We determined the spectral level and the corner frequency by fitting the $\omega^{2}$ model (Boatwright, 1978) with an attenuation correction following the method of Ide et al. (2003), after correcting for the instrument response. We estimated the observed amplitude from the spectral level. The best-fitting focal mechanism solution for each event was determined by minimizing the residual between the observed and theoretical amplitudes. A grid search approach was used to determine the strike, dip, and rake angles at $5^{\circ}$ intervals. We obtained the focal mechanism solutions for 822 events that satisfied the following two conditions: (1) the number of $P$-wave polarities was $\geq 12$ and (2) the magnitude of the event was $\leq 3.0$. In order to calculate the azimuth and 


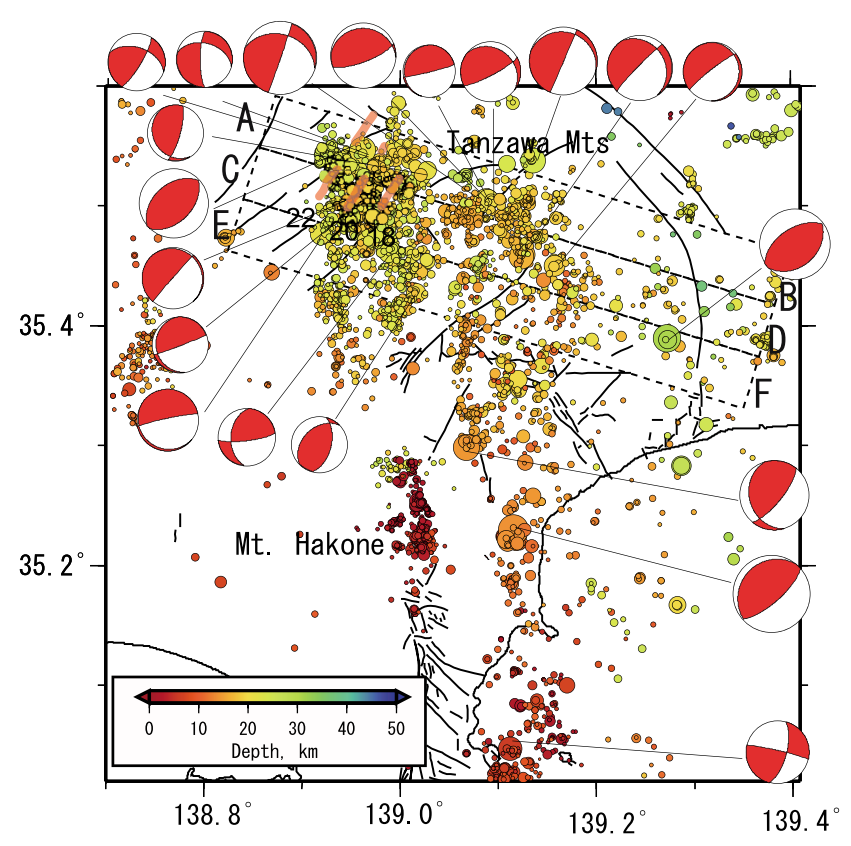

Fig. 2. Epicentral distribution of the relocated hypocenters in the Izu-Honshu collision zone. Colors of circles signify the depth of hypocenters. The focal mechanisms of the earthquakes with magnitudes greater than 3.0 are also shown in lower hemisphere projections. The thin black lines indicate surface traces of active faults (Research Group for Active Faults of Japan, 1991). Rectangles A-B, C-D, and E-F correspond to the depth sections indicated in Fig. 3. The red broken lines indicate the depth contours of the conversion plane obtained by the inversion of arrival time data of $S-P$ converted waves (Tsumura et al., 1993).

take-off angle of the focal mechanisms, we used the relocated hypocenter locations. Then, we applied the amplitude station corrections, according to the procedure reported by Imanishi et al. (2006). We estimated the uncertainty in the focal mechanism solution from the standard deviation of the rotation angles (Kagan, 1991) between the best-fitting solution and all of the solutions for which the residual was less than 1.1 times the minimum residual. The average error of all of the focal mechanisms was $6^{\circ}$. For earthquakes having magnitudes greater than 3.0, we used the moment tensor solutions of the NIED F-net catalog. Variance reductions (VRs) of the moment tensor solutions used in the present study are greater than $70 \%$. According to Fukuyama et al. (1998), a moment tensor solution with a VR of greater than $70 \%$ is reliable. The error for $P$ - and $T$-axes is generally within $5^{\circ}$.

\section{Distribution of Hypocenters and Focal Mecha- nisms}

\subsection{Relocated hypocenter distribution}

Figure 2 shows the epicenter distribution of the relocated hypocenters in and around the Tanzawa Mountains. The earthquakes beneath the Tanzawa Mountains (defined as the Tanzawa region) are distributed in the depth range from $10 \mathrm{~km}$ to $30 \mathrm{~km}$. The seismicity at Mount Hakone (Fig. 2) represents shallow swarm earthquakes associated with the geothermal activity of Hakone volcano (e.g., Yukutake et $a l ., 2010)$. In order to clarify the relation between the seismicity in the Tanzawa region and the subducting PHS

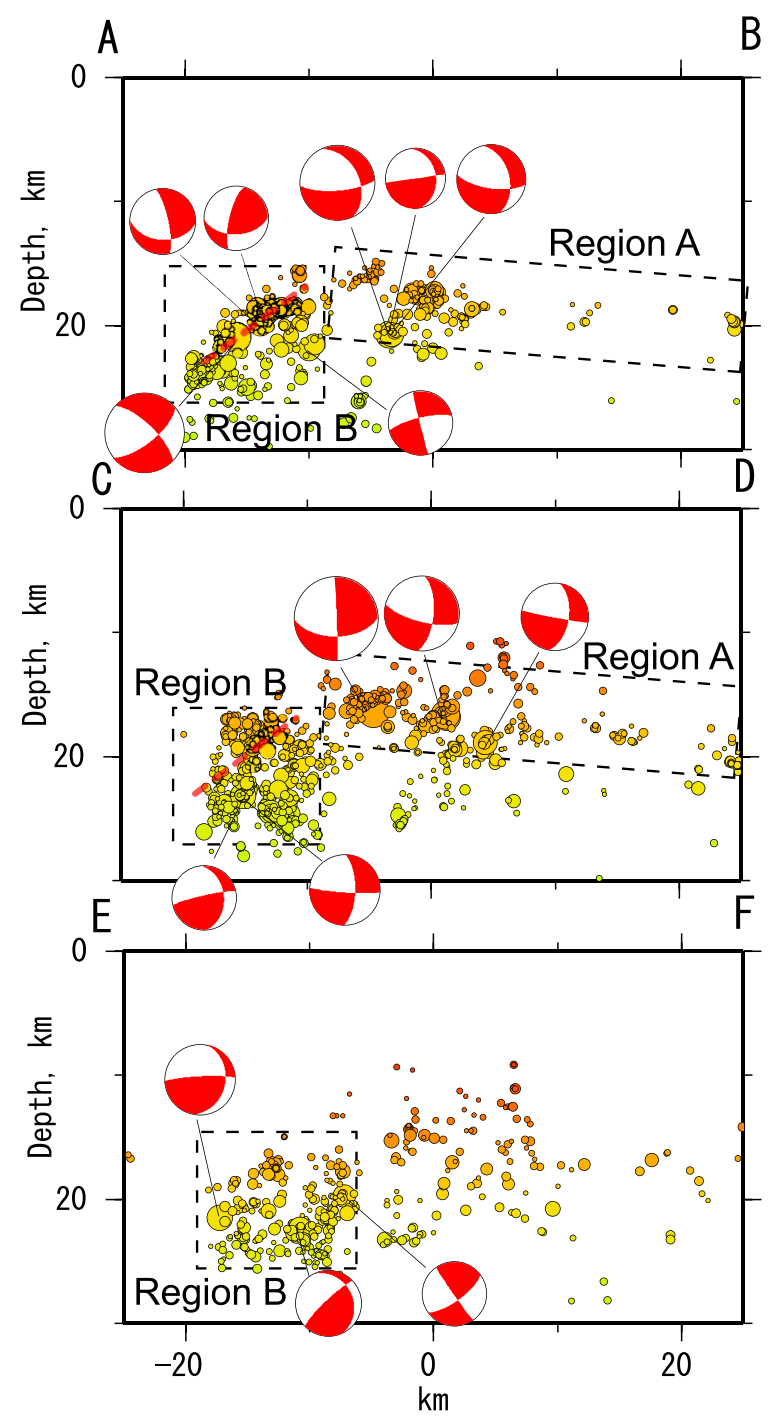

Fig. 3. Depth sections along lines A-B, C-D, and E-F shown in Fig. 2. The focal mechanisms with magnitudes $\geq 3.0$ are also shown. As in Fig. 2, the colors indicate the depths of the hypocenters. The broken lines indicate the location of the conversion plane estimated by Tsumura et al. (1993). The red broken rectangles indicate Regions A and B, which were selected as the reference areas.

plate, we show depth sections of the hypocenters in Fig. 3 for the rectangle areas along lines $\mathrm{A}-\mathrm{B}, \mathrm{C}-\mathrm{D}$, and $\mathrm{E}-\mathrm{F}$ shown in Fig. 2. The direction of these depth sections is approximately parallel to the strike of the upper surface of the PHS plate under the Tanzawa region, as estimated in previous studies (e.g., Ishida, 1992; Sato et al., 2005).

We found that the characteristics of the hypocenter distribution differ between the eastern and western parts of the Tanzawa region. In the eastern part, the earthquakes appear to be distributed within a horizontal zone. (We defined this area as Region A, as indicated by the broken-line rectangles in Fig. 3). On the other hand, in the western part, the earthquakes are distributed in a volume of approximately $10 \mathrm{~km} \times 10 \mathrm{~km} \times 10 \mathrm{~km}$. (We defined this block as Region B.) The feature of the scattered distribution appears clearly in depth sections C-D and E-F (Fig. 3). Note that the focal mechanisms of major earthquakes in the Tanzawa region are thrust or right-lateral reverse faulting type mechanisms 
(Fig. 2). The $P$-axes range from the NW-SE to NNW-SSE directions. One of the nodal planes of these focal mechanisms in Region A appears to be consistent with the horizontal alignment of the hypocenter distribution (Fig. 3).

\subsection{Detailed spatial distribution of focal mechanisms}

In order to investigate the detailed features in the spatial distribution of the focal mechanisms, we estimated representative reference focal mechanisms. The reference mechanism and a comparison of the reference mechanism and the observed mechanisms provide important information concerning the characteristics of the focal mechanism distribution in the study region. We used the Kagan angle (Kagan, 1991) to evaluate the similarity between the reference and observed focal mechanisms. The reference focal mechanism minimizes the sum of squares of the Kagan angles between the reference and observed focal mechanisms. We sought the best reference focal mechanism using a grid search for the pole of the nodal plane and the rake angle using $10^{\circ}$ grid intervals. We estimated the reference mechanisms of earthquakes in Region A (Reference mechanism A).

Figure 4(a) and Table 1 show Reference mechanism A and its fault parameters for the nodal planes, respectively. Reference mechanism A is a right-lateral reverse fault having a nodal plane dipping slightly to the NNE-SSE direction. The focal mechanism is classified as 'other' type according to the definition of Frohlich (1992). The strike and dip angle of one of the nodal planes for Reference mechanism A are consistent with the geometry of the PHS plate in the eastern part of the Tanzawa region (e.g., Ishida, 1992; Sato et al., 2005) and the fault parameters of the 1923 Kanto Earthquake (Matsu'ura et al., 1980; Kobayashi and Koketsu, 2005). The rake angle of Reference mechanism A is also consistent with the relative motion of the PHS plate with respect to the Eurasian plate in the Kanto region (Seno, 1993).

Figures 5(a)-(c) show the spatial distribution of the Kagan angles between Reference mechanism A and the observed focal mechanisms on depth sections A-B, C-D, and E-F, respectively. The frequency distributions of the Kagan angles for earthquakes that occurred in Regions A and B are indicated in Fig. 6(a). The Kagan angles are small for many of the focal mechanisms that occurred in Region A (Figs. 5(a) and (b)). In fact, the Kagan angles for most of the earthquakes in Region A are less than $40^{\circ}$ (Fig. 6(a)). On the other hand, the Kagan angles for a number of focal mechanisms in Region B, especially in the deep part of Region B, are rather large (Figs. 5(a)-5(c)), although several focal mechanisms in the shallow part of Region $B$ on depth sections A-B and C-D exhibit small Kagan angles. A feature of bimodal peaks is observed in the frequency distribution of the Kagan angle in Region B (Fig. 6(a)). The peak of large Kagan angles around $60^{\circ}$ corresponds to the earthquakes that occurred in the deep part of Region B. These results indicate that at least the focal mechanisms in this part differ substantially from those in Region A.

In order to clarify the focal mechanisms in the deep part of Region B, we divided Region B into two subregions, Regions B-1 and B-2, based on the focal mechanism distribution shown in Figs. 5(a)-(c). Using the same procedure (a) Reference Mechanism A

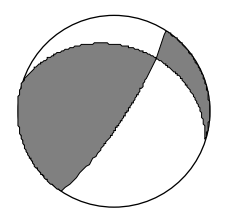

(b) Reference Mechanism B

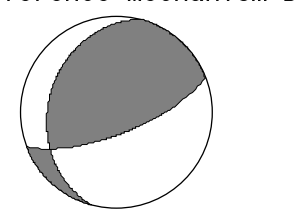

Fig. 4. Reference focal mechanisms for (a) Region A and (b) Region B, shown in lower hemisphere projections.

Table 1. Fault parameters of the nodal planes for Reference mechanisms $\mathrm{A}$ and $\mathrm{B}$.

\begin{tabular}{cccc}
\hline & Strike & Dip & Rake \\
\hline Reference A & $287 / 33$ & $32 / 80$ & $161 / 59$ \\
Reference B & $195 / 69$ & $30 / 71$ & $40 / 114$ \\
\hline
\end{tabular}

for Region A, we estimated the reference focal mechanism (Reference mechanism B) for the earthquakes in Region B2. Figure 4(b) and Table 1 show Reference mechanism B and its fault parameters for the nodal planes, respectively. Reference mechanism B is a focal mechanism having a nodal plane dipping to the WNW-ESE direction, which is classified as a thrust type mechanism according to the definition of Frohlich (1992). A number of the earthquakes in Region B have focal mechanisms with small Kagan angles from Reference mechanism B (Figs. 5(d)-(f)). The Kagan angles from Reference mechanism $B$ are less than $40^{\circ}$ for many of the earthquakes in Region B (Fig. 6(b)). The peak at the Kagan angle of $50^{\circ}$ from Reference mechanism $B$ in Region B represents the earthquakes that occurred in Region B-1 (Figs. 5(a) and (b)).

\section{Stress Inversion}

We quantitatively analyzed the stress fields, using the stress inversion method developed by Horiuchi et al. (1995). The directions of the principal stress and the stress ratio $R=\left(\sigma_{1}-\sigma_{2}\right) /\left(\sigma_{1}-\sigma_{3}\right)$, where $\sigma_{1}, \sigma_{2}$, and $\sigma_{3}$ are the maximum, intermediate, and minimum principal stress, respectively, are estimated directly from the $P$-wave polarity data. Using the $P$-wave polarity data to determine the stress parameters, we could avoid a priori selection of the fault plane between two nodal planes and evaluate the uncertainties in the stress parameters more accurately than by using the stress inversion method based on data of the focal mechanisms. In the analysis, we used only data for which the number of inconsistent polarities for the best focal mechanism was less than two. We performed a grid search for the direction of the principal stress axes with $10^{\circ}$ intervals and for $R$ with 0.025 intervals. We repeated the grid search in order to determine the best solutions of the principal stress axis directions with $2^{\circ}$ grid intervals in the vicinity of the principal stress axis obtained by the first grid search. We estimated the uncertainty for each stress parameter by performing 2,000 bootstrap resamplings (Michael, 1987) of the entire data set within each region.

Figures 7(a) and (b) show the results of the stress inversion analysis for Regions $\mathrm{A}$ and $\mathrm{B}$, respectively. The azimuths of the $\sigma_{1}$ axes in both regions range from the NW-SE direction to the NNW-SSE direction, and $R$ is 

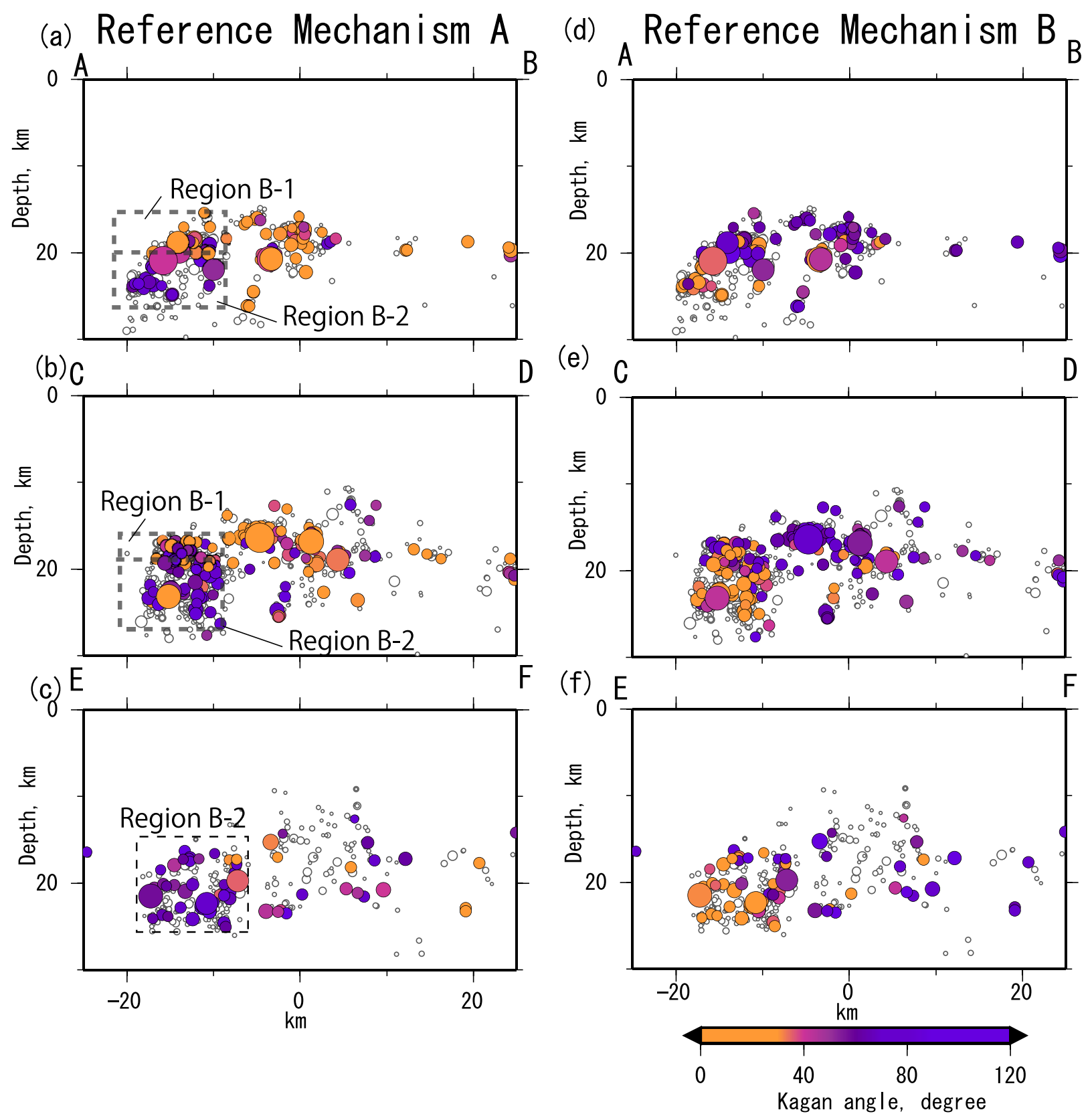

Fig. 5. Kagan angles between the focal mechanisms of earthquakes in depth sections A-B, C-D, and E-F and Reference mechanisms A and B are shown in (a)-(c) and (d)-(f), respectively. The colors indicate the values of the Kagan angle for each focal mechanism. Gray circles indicate earthquakes having focal mechanisms that could not be successfully determined.

approximately 0.6. The $\sigma_{3}$ axes in Region $\mathrm{B}$ are approximately in the vertical direction, which is considered to reflect the dominance of thrust type earthquakes as represented by Reference mechanism B. In general, the results of the stress inversion are consistent with the regional stress field around the Tanzawa region estimated in previous studies (e.g., Townend and Zoback, 2006).

On the other hand, a small but significant difference appears in the stress field between Regions A and B. While the plunges of the $\sigma_{1}$ and $\sigma_{3}$ axes in Region $\mathrm{B}$ are closer to the horizontal and vertical directions, respectively, those in Region A are both inclined slightly. The stress state in Region A reflects Reference mechanism A, which has a larger strike-slip component than Reference mechanism B. In order to quantitatively evaluate whether the plunge of the $\sigma_{1}$ axis differs between the two regions, we calculated the probability density function of the difference in the plunge of the $\sigma_{1}$ axis following the method developed by Michael (1987). In this method, the probability density function can be estimated by comparing 2,000 bootstrap results in the two regions. The confidence that the rotation angle of the $\sigma_{1}$ plunge between Regions $\mathrm{A}$ and $\mathrm{B}$ is greater than $0^{\circ}$ is $97 \%$. Therefore, the difference of the plunge of the $\sigma_{1}$ axis is considered to be statistically significant with a confidence level greater than $95 \%$.

Since focal mechanisms with small Kagan angles from Reference mechanism A are observed in the shallow part of Region B (Region B-1 in Figs. 5(a) and (b)), the stress field in the region may be similar to that in Region A. Figures 7 (c) and (d) show the stress inversion results for 


\section{(a) Reference Mechanism A}

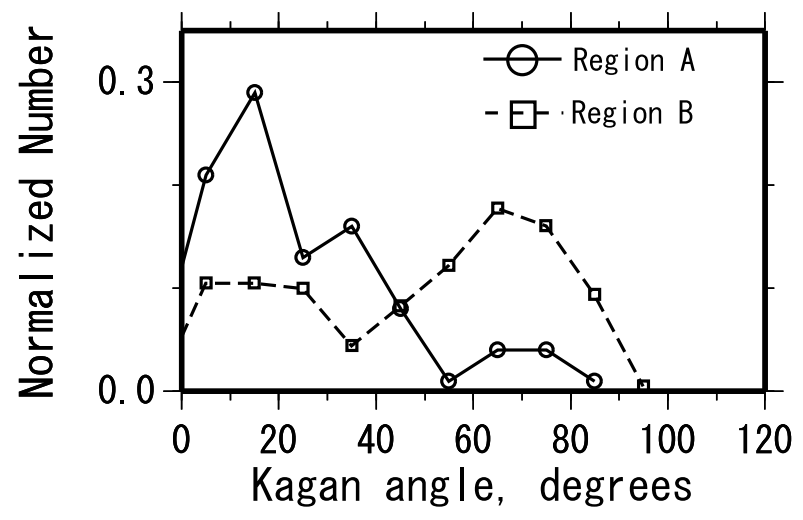

(b) Reference Mechanism B

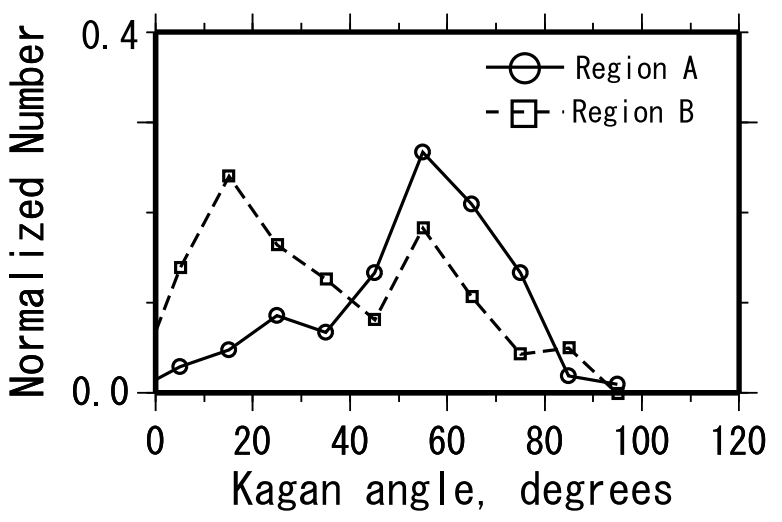

Fig. 6. Frequency distribution of the Kagan angle for earthquakes that occurred in Regions A and B. (a) Reference A, (b) Reference B. The $Y$ axis is normalized by the total number of events in each region.

Regions B-1 and B-2. The best stress parameters and their 95\% confidence regions are similar to those in Region B. Moreover, the $95 \%$ confidence regions in Regions B-1 and B-2 overlap each other. These results suggest that the stress field does not differ significantly within Region B, although several focal mechanisms similar to Reference mechanism A are observed in the shallow part of Region B.

\section{Discussion}

We found that the earthquakes in Region A tend to be distributed within a horizontal zone (Fig. 3) that is approximately parallel to the upper surface of the PHS plate. One of the nodal planes of Reference mechanism A is in agreement with the upper surface geometry of the PHS plate in the eastern part of the Tanzawa region estimated in previous studies (e.g., Ishida, 1992; Sato et al., 2005) and the fault parameters of the 1923 Kanto earthquake (e.g., Matsu'ura et al., 1980). The rake angle of Reference mechanism A is consistent with the relative plate motion (Seno, 1993). Most of the earthquakes in Region A have small Kagan angles from Reference mechanism A (Fig. 6(a)). These results strongly suggest that earthquakes occur in Region A, reflecting the subduction process of the PHS plate.

The seismic velocity tomography revealed that a lowvelocity wedge exists between the Tanzawa Mountains and Mount Hakone (Nakamichi et al., 2007; Nagai and Tanada, 2010). These studies interpreted the low-velocity wedge as trough-filled deposits, which accreted between the Tanzawa and Izu block. Nagai and Tanada (2010) found that the earthquakes in the eastern part of the Tanzawa region (Region A) occur along the velocity boundary under the low-velocity wedge (the boundary between trough-filled deposits and the Izu block). The fact that the focal mechanisms of the earthquakes in Region A are consistent with the configuration of the PHS plate probably indicates that the velocity boundary corresponds to the upper surface of the subducting PHS plate (Figs. 5(a) and 4(b)). In addition, small alignments of the earthquakes dipping to the WNW direction appear on depth sections A-B and C-D for Region $\mathrm{A}$ (near the point given by $X=0 \mathrm{~km}$ at a depth of $19 \mathrm{~km}$ in Fig. 3). This feature might indicate the develop- ment of small fractures near the plate boundary.

The plunges of the $\sigma_{1}$ and $\sigma_{3}$ axes in Region A were found to be slightly inclined (Fig. 7(a)). Such a feature of the stress state was also reported in the Hikuragi subduction zone, New Zealand, where the $\sigma_{3}$ axis is closely inclined to the dip direction of the plate (McGinty et al., 2000). McGinty et al. (2000) interpreted that the stress state was caused by the slab pull effect from the deeper part of the subducting plate. Wide-angle reflection analysis (Arai et al., 2009) revealed that the subducting PHS plate is extended to the area beneath the Kanto Mountains. The stress field in Region A may be caused by the pull force induced from the deeper part of the subducting slab.

Reference mechanism B represents a thrust type mechanism having a nodal plane dipping to the WNW-ESE direction, which is significantly different from Reference mechanism $\mathrm{A}$. The conversion plane obtained by the inversion of arrival time data of $S$ - $P$ converted waves (Tsumura et al., 1993) is located at the upper limit of the hypocenter distribution in Region B (Figs. 2 and 3). Tsumura et al. (1993) interpreted the conversion plane as the upper surface of the PHP plate in the western part of the Tanzawa region. Since hypocenters in Region $\mathrm{B}$ are distributed in a volume rather than along a horizontal zone, most of the earthquakes in Region B are assumed to occur within the PHS plate. Arai (2011) hypothesized that a fracture zone is developed within the Izu block associated with crustal delamination process. The focal mechanisms in Region B characterized by Reference mechanism B might reflect the fracture structure developed within the PHS plate.

Based on the characteristics of the hypocenter distribution, Yoshida (1993) and Ishikawa (2007) proposed that a tectonic boundary of the $\mathrm{N}-\mathrm{S}$ strike exists between the eastern and western parts beneath the Tanzawa Mountains. The proposed tectonic boundary corresponds to the boundary between Regions A and B in the present study (Fig. 8). Yoshida (1993) suggested that the seismicity in the western side of the boundary is caused by the collision between the Izu and Honshu blocks, whereas that in the eastern side reflects the subduction process of the PHS plate. Based on the velocity structures estimated by the refraction/wide- 
(a) Region $\mathrm{A}$

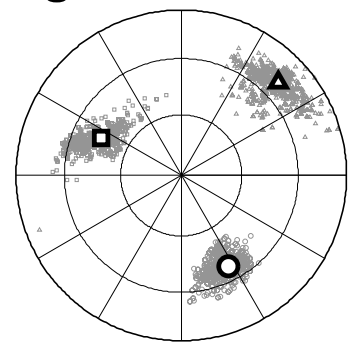

$\sigma 1$ azimuth, plunge $=152,38$ $\sigma 3$ azimuth, plunge $=295,44$ Misfit $=2.4 \%$

(b) Region $B$

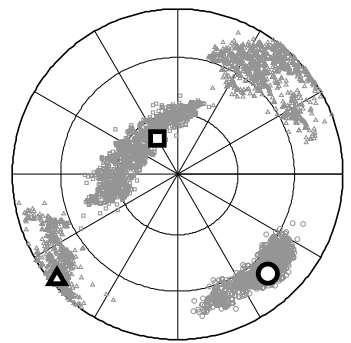

$\sigma 1$ azimuth, plunge $=137,19$ $\sigma 3$ azimuth, plunge $=330,70$ Misfit $=3.7 \%$

\section{(c) Reg i onB-1}

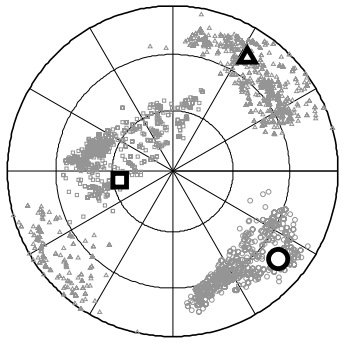

$\sigma 1$ azimuth, plunge $=130,18$ $\sigma 3$ azimuth, plunge $=260,63$ Misfit $=3.1 \%$

\section{(d) Region B-2}

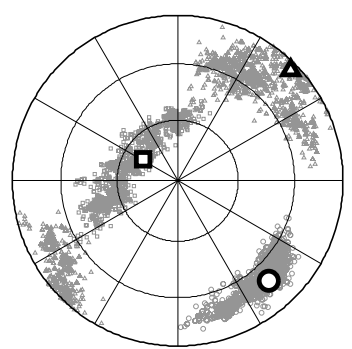

$\sigma 1$ azimuth, plunge $=137,19$ $\sigma 3$ azimuth, plunge $=302,70$ Misfit $=3.7 \%$
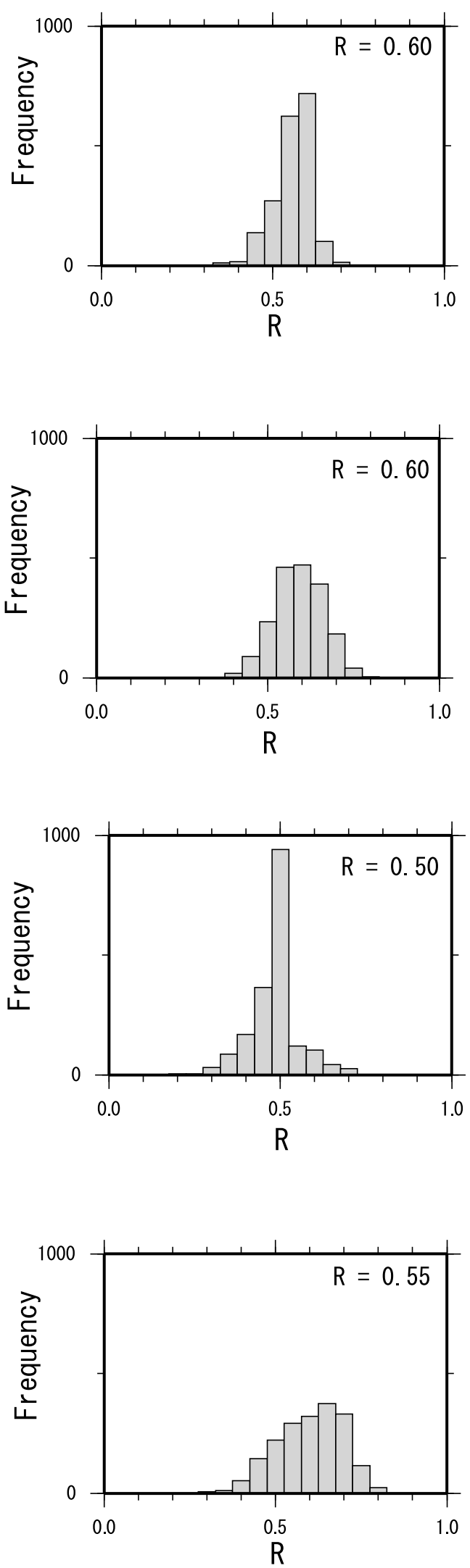

Fig. 7. Stress inversion results in (a) Region A and (b) Region B. (Left) The best directions of the principal stress ( $\sigma_{1}$, large circle; $\sigma_{2}$, large triangle; $\sigma_{3}$, large rectangle) and their $95 \%$ confidence regions $\left(\sigma_{1}\right.$, small circles; $\sigma_{2}$, small triangles; $\sigma_{3}$, small rectangles) are plotted in lower hemisphere projections. The numerals below the stereo-net show the azimuths and plunges of the best principal stress axes. The plunge is the angle of inclination measuring clockwise from horizontal plane. The misfit is shown as the ratio of the number of the inconsistent polarities to that of all of the polarities. (Right) Frequency distribution of $R$ within the $95 \%$ confidence level. 


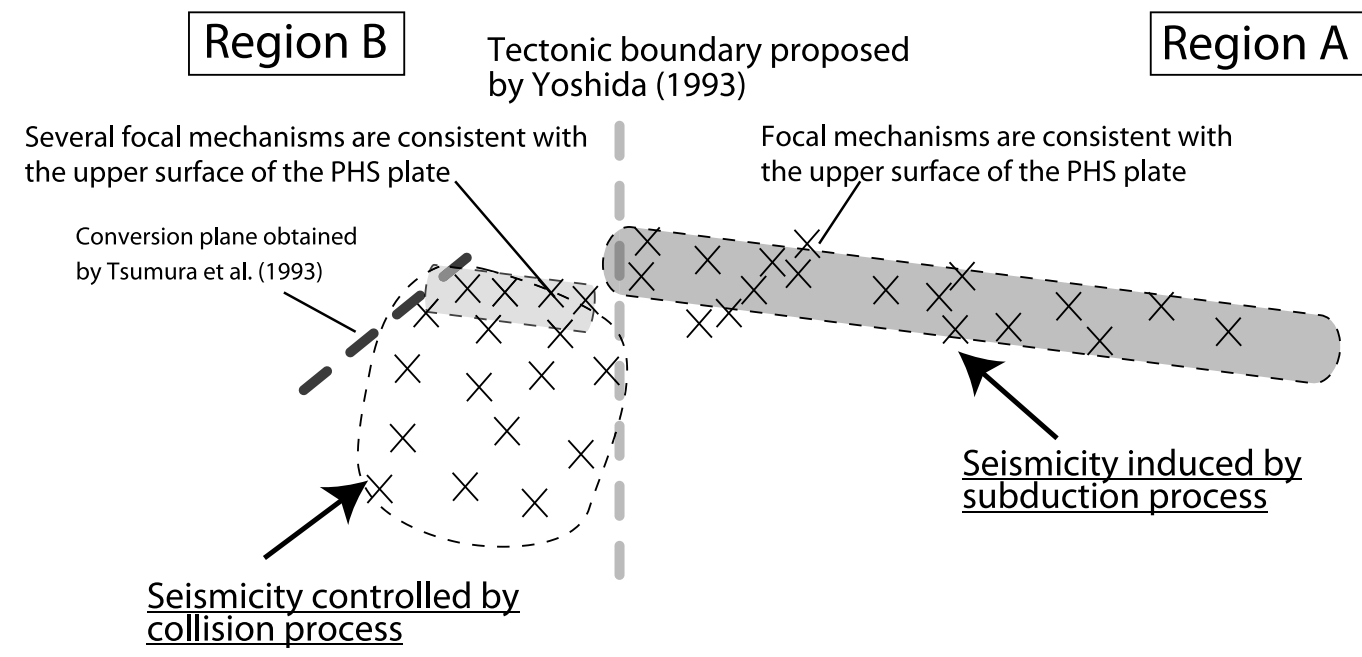

Fig. 8. Schematic diagram showing the seismotectonic situation beneath the Tanzawa Mountains with reference to the subduction and collision process of the PHS plate.

angle reflection analyses, Arai (2011) showed that the collision feature is more prominent in the western part of the Tanzawa region, as compared with that in the eastern part. The results of the present study indicate that the $\sigma_{1}$ axis in Region B is closer to the horizontal direction, as compared to that in Region A (Fig. 7). This also suggests a difference in tectonic situations between the two regions. The stress state in Region B is considered to be controlled by the collision process between the Izu and Honshu blocks, whereas that in Region A reflects the subduction process of the PHS plate (Fig. 8). Note that the focal mechanisms with the small Kagan angles from Reference mechanism A are also observed in the shallow part of Region B (Figs. 5(a) and (b)). However, as we indicated, the stress field in the shallow part of Region B (Fig. 7(c)) is approximately the same as that in the overall Region B (Fig. 7(b)), and the seismicity in Region B is likely controlled primarily by the collision process, even in the shallow part.

\section{Conclusions}

We investigated the distribution of hypocenters, focal mechanisms, and stress states beneath the Tanzawa Mountains located in the Izu-Honshu collision zone. We found that characteristics of the hypocenter distribution and focal mechanisms clearly differ between the eastern and western parts of the Tanzawa region. The hypocenters of the earthquakes in the eastern part tend to be distributed within a horizontal zone, whereas the hypocenters of the earthquakes in the western part are distributed in a volume. The focal mechanisms of the right-lateral reverse fault representative in the eastern par are consistent with the configuration of the upper surface of the PHS plate. The focal mechanisms in the eastern part differ from those in the western part. Most of the earthquakes in the eastern part beneath the Tanzawa region are considered to occur along the upper surface of the subducting PHS plate, whereas those in the western part occur within the PHS plate. The stress state in the eastern part is significantly different from that in the western part. The plunges of the $\sigma_{1}$ and $\sigma_{3}$ axes in the eastern part are slightly inclined. The stress state may be induced by a pull force caused by the deeper part of the subducting slab.

Acknowledgments. We are grateful to Dr. F. Waldhauser for providing the hypoDD program code. Dr. Satoshi Ide provided the program used to estimate the focal mechanisms. We would also like to thank the two anonymous reviewers who greatly helped us to improve the manuscript and Dr. Tomomi Okada for editing the manuscript. Dr. Makoto Matsubara provided helpful information about the three-dimensional velocity structure in the study area. We would also like to thank the National Research Institute for Earth Science and Disaster Prevention (NIED) Hi-net and the Japan Meteorological Agency for allowing us to use the waveform data. We used the moment tensor catalog determined by NIED Fnet. The majority of the figures were created using the Generic Mapping Tools (GMT) (Wessel and Smith, 1995).

\section{References}

Arai, R., Multiple collision and subduction structure of the Izu-Bonin arc revealed by integrated analysis of active and passive source seismic data, Doctoral thesis, Tokyo University, 126 pp., 2011.

Arai, R., T. Iwasaki, H. Sato, S. Abe, and N. Hirata, Collision and subduction structure of the Izu-Bonin arc, central Japan, revealed by refraction/wide-angle reflection analysis, Tectonophysics, 475, 438453, 2009.

Boatwright, J., Detailed spectral analysis of two small New York State earthquakes, Bull. Seismol. Soc. Am., 68, 1131-1177, 1978.

Frohlich, C., Triangle diagrams: ternary graphs to display similarity and diversity of earthquake focal mechanisms, Phys. Earth Planet. Inter., 75, 193-198, 1992.

Fukuyama, E., M. Ishida, D. S. Dreger, and H. Kawai, Automated seismic moment tensor determination by using on-line broadband seismic waveforms, Bull. Seismol. Soc. Jpn., 51, 149-156, 1998 (in Japanese with English abstract).

Hiraga, S., Seismicity of Hakone volcano and it adjacent area, Bull. Hot Springs Res. Inst. Kanagawa Pref., 18, 125 pp., 1987 (in Japanese).

Hirata, N. and M. Matsu'ura, Maximum-likelihood estimation of hypocenter with original time eliminated using nonlinear inversion technique, Phys. Earth Planet. Inter., 47, 50-61, 1987.

Horiuchi, S., G. Rocco, and A. Hasegawa, Discrimination of fault planes from auxiliary planes based on simultaneous determination of stress tensor and a large number of fault plane solutions, J. Geophys. Res., 100, 8327-8338, doi:10.1029/94JB03284, 1995.

Ide, S., G. C. Beroza, S. G. Prejean, and W. L. Ellsworth, Apparent break in earthquake scaling due to path and site effects on deep borehole recordings, J. Geophys. Res., 108(B5), doi:10.1029/2001JB001617, 2003.

Iidaka, T., M. Mizoue, I. Nakamura, T. Tsukuda, K. Sakai, M. Kobayashi, T. Haneda, and S. Hashimoto, The upper boundary of the Philippine Sea plate beneath the western Kanto region estimated from S-P-converted 
wave, Tectonopysics, 179, 321-326, 1990.

Imanishi, K., Y. Kuwahara, T. Takeda, and Y. Haryu, The seismicity, fault structures, and stress field in the seismic gap adjacent to the 2004 MidNiigata earthquake inferred from seismological observations, Earth Planets Space, 58, 831-841, 2006.

Ishida, M., Geometry and relative motion of the Philippine Sea Plate and Pacific Plate beneath the Kanto-Tokai district, Japan, J. Geophys. Res., 97, 489-513, 1992.

Ishikawa, M, Seismotectonics and petrological model for structure of the Izu collision zone, Chikyu Mon., 57, 166-172, 2007.

Kagan, Y. Y., 3-D rotation of double-couple earthquake sources, Geophys. J. Int., 106, 708-716, 1991.

Kaizuka, S., A tectonic model for the morphology of arc-trench system, especially for the echelon ridges and mid-arc faults, Jpn.J. Geol. Geogr., 45, 9-28, 1975.

Kobayashi, R. and K. Koketsu, Source process of the 1923 Kanto earthquake inferred from histrical geodetic, teleseismic, and strong motion data, Earth Planets Space, 57, 261-270, 2005.

Matsubara, M., H. Hayashi, K. Obara, and K. Kasahara, Low-velocity oceanic crust at the top of the Phillipine Sea and Pacific plates beneath the Kanto region, central Japan, imaged by seismic tomography, J. Geophys. Res., 110, B12304, 2005.

Matsu'ura, M., T. Iwasaki, Y. Suzuki, and R. Sato, Statical and dynamical study on faulting mechanism of the 1923 Kanto earthquake, J. Phys. Earth, 28, 119-143, 1980.

McGinty, P., M. Reyners, and R. Robinson, Stress directions in the shallow part of the Hikurangi subduction zone, New Zealand, from the inversion of earthquake first motions, Geophys. J. Int., 142, 339-350, 2000.

Michael, A. J., Stress rotation during the Coalinga aftershock sequence, $J$. Geophys. Res., 92, 7963-7979, doi:10.1029/JB092iB08p07963, 1987.

Nagai, S. and T. Tanada, Seismic velocity structures and relocated seismicity in the northeast are of the Izu Collision Zone, Abstract of Japan Geoscience Union Metting 2010, SSS024-04, Makuhari Chiba Japan, 2010.

Nakamichi, H., H. Wabanabe, and T. Ohminato, Three-dimensional velocity structures of Mount Fuji and the South Fossa Magna, central Japan, J. Geophys. Res., 112, B03310, doi:10.1029/2005JB004161, 2007.

Noguchi, S. and A. Yoshida, Recent seismic activity in the eastern Yamanashi Prefecture and its tectonic implications, Bull. Seismol. Soc. Jpn., 44, 247-258, 1991 (in Japanese with English abstract).

Obara, K., K. Kasahara, S. Hori, and Y. Okada, A densely distributed highsensitivity seismograph network in Japan: Hi-net by National Research
Institute for Earth Science and Disaster Prevention, Rev. Sci. Instrum., 76, 021301, doi:10.1063/1.1854197, 2005.

Research Group for Active Faults of Japan, Active Faults in Japan, revised edition, edited by University of Tokyo Press, 437 pp., 1991 (in Japanese).

Sato, H., N. Hirata, K. Koketsu, D. Okaya, S. Abe, R. Kobayashi, M. Matsubara, T. Iwasaki, T. Ito, T. Ikawa, T. Kawanaka, K. Kasahara, and S. Harder, Earthquake source fault beneath Tokyo, Science, 309, 462464, 2005.

Seno, T., Relative plate motions in the Kanto-Tokai District, J. Geogr., 102, 374-380, 1993.

Shearer, P., Improving local earthquake locations using the L1 norm and waveform cross correlation: Application to the Whittier Narrows, California, aftershock sequence, J. Geophys. Res., 102, 8269-8283, 1997.

Taira, A., S. Saito, K. Aoike, S. Morita, H. Tokuyama, K. Suyehiro, N. Takahashi, M. Shinohara, S. Kiyakawa, J. Naka, and A. Klaus, Nature and growth rate of the Northern Izu-Bonin (Ogasawara) arc crust and their implications for continental crust formation, Island Arc, 7, 395407, 1998.

Townend, J. and M. D. Zoback, Stress, strain and mountain building in central Japan, J. Geophys. Res., 111, B03411, doi:10.1029/2005JB003759, 2006.

Tsumura, N., S. Horiuchi, A. Hasegawa, and K. Kasahara, Location of the upper boundary of the Philippine Sea Plate beneath the eastern part of Yamanashi Prefecture estimated from S to P converted waves, Bull. Seismol. Soc. Jpn., 46, 109-118, 1993 (in Japanese with English abstract).

Waldhauser, F. and W. L. Ellsworth, A double-difference earthquake location algorithm: Method and application to the Northern Hayward fault, Bull. Seismol. Soc. Am., 90, 1352-1368, 2000.

Wessel, P. and W. H. F. Smith, New version of the generic mapping tools released, Eos Trans. AGU, 76, 329, 1995.

Yoshida, A., Seismic activities and tectonics in and around Western Kanagawa, J. Geogr., 102, 407-417, 1993.

Yukutake, Y., T. Tanada, R. Honda, M. Harada, H. Ito, and A. Yoshida, Fine fracture structures in the geothermal region of Hakone volcano, revealed by well-resolved earthquake hypocenters and focal mechanisms, Tectonophysics, 489, 104-118, 2010.

Y. Yukutake (e-mail: yukutake@onken.odawara.kanagawa.jp), T. Takeda, R. Honda, and A. Yoshida 